\title{
An Assessment of Global Civilizational State, Evolutionity, Along with Global Solidarity and United Citizens Movement
}

\author{
Germain Joseph Dufour \\ Department of Physics, University of Quebec at Trois-Rivieres, Quebec, Canada
}

Email address:

globalcommunity@telus.net, gdufour@globalcommunitywebnet.com

\section{To cite this article:}

Germain Joseph Dufour. An Assessment of Global Civilizational State, Evolutionity, Along with Global Solidarity and United Citizens Movement. International Journal of Philosophy. Special Issue: Evolutionity. Vol. 8, No. 1, 2020, pp. 22-33. doi: 10.11648/j.ijp.20200801.14

Received: February 21, 2020; Accepted: March 16, 2020; Published: April 1, 2020

\begin{abstract}
As global crises of all sorts on our planet further intensify, Global Community may have no alternative but to show Global Solidarity and help each other out of crises. Such solidarity can only be built on the basis of harmony, cooperation and moderation, and on respecting the political and cultural diversity of our multicivilizational troubled world. Global Civilizational State and Evolutionity are proposing creative works toward saving humanity from self-destruction, and are a complex mix of higher levels of morality, religion, education, art, philosophy, technology, and material wellbeing. In fact both are also a continuation from the previous Modernity epoch inspired by the mechanistic and deterministic view of societies, and Postmodernity epoch been born out of our dissatisfaction with modernity, and characterized by issues related to the global warming of the planet, globalization, political instability and a social and political regress to irrationality. As Global Civilizational State and Evolutionity along with Global Solidarity and United Citizens Movement begin to take on a much deeper kind of global leadership, one that earns more respect than envy and more gratitude than hatred, one that can catapult the whole planet forward into a future where war is no longer thinkable between nation-states, and a legitimate and beneficial Earth governance is able to cope with global problems.
\end{abstract}

Keywords: Modernity Postmodernity Evolutionity, Global Civilizational State, Global Symbiotical Relationship, Global Parliament Global Government, Global Solidarity, Scale of Gobal Right,

Global Trade and Resources Ministry, Harmony Cooperation Peace Morality Ethic

\section{Evolutionity}

\subsection{Global Leadership Is Needed to Help Develop and Apply Surviving Solutions for Life on Earth}

Environmental problems have contributed to numerous collapses of civilizations in the past. Now, for the first time, a global collapse appears likely and global warming, overpopulation, overconsumption by the rich, and poor choices of technologies are major drivers. Truly, the world is on the threshold of a global change and needs to proceed with the non-violent approach. Global Leadership is needed to help develop and apply surviving solutions for Life on Earth. We can no longer perceive ourselves as a People who could survive alone and a People who does not need anyone else. We belong to and depend on this much larger group, that of Global Community. Global cooperation brings people together for a common future for the good of all. Global
Community was built from a grassroots process with a vision for humanity that is challenging every person on Earth as well as nation governments and has a vision of the people working together, building a new civilization- Global Civilizational State, including a healthy and rewarding future for the next generations. [1]

\subsection{Evolutionity Aiming at Saving Humanity from Self-destruction by Creating and Promoting Social Harmony"}

An important proposal was brought forward by Prof. W. Julian Korab-Karpowicz with his innovative, original "Evolutionity" work aimed at saving humanity from selfdestruction. From one moment in history with modernizing the world, to the next step being post modernizing, and finally to the historical and ultimate future of humanity, the new evolutionary epoch, Evolutionity is helping us to overcome the narrow materialistic and deterministic 
interpretations of reality. As global crises of all sorts on our planet intensify critically, it is clear that the actual picture of the world now includes both old and new global issues such as poverty, crime, religious and ethnic conflict, terrorism, global warming, climate change, energy scarcity, and so on. These issues are further magnified by the widening spread and quickening pace of globalization. To deal effectively with them, one has to work on many levels of governance such as those international organizations based on the United Nations (UN) and to expand global governance by including Global Solidarity or the United Citizens organization (UC) based on Non-Government Organizations (NGOs). To get out of the global crises and thus to save ourselves as a species from self-destruction, we must recognize and promote our true human identity and our destiny as humankind. Evolutionity is inspired by the idea of human evolution and by the organic and holistic worldview emerging from science. It involves thinking and speaking meaningfully about values. It is expressed in politics aimed at a good life for the whole of humankind. A good life is not only the wealth or material prosperity of human beings, but also moral virtues and intellectual development, and embracing a comprehensive and evolutionary view of reality. It is the world of social harmony. Social harmony is applicable to both domestic politics and international relations, it is indispensable for happiness and good life, and thus for solving global challenges. [2-5]

\subsection{Earth Governance Is About the Rights of Nation-states to Self-determination in the Global Context of Global Civilizational State.}

In 1985, another proposal was researched and developed by the author of this Paper who put forward surviving solutions for Life on Earth and a system of global governance. This system would consist of nine or more Global Governments described within the largest cultural groupings of people on Earth - Global Civilizational State. In such system core states would play a leading role, that is a variety of cultures, civilizations, religious worlds, historical traditions, and nation-states. Earth governance is about the rights of nation-states to self-determination in the global context of Global Civilizational State rather than the traditional context of a world of separate states. Earth governance does not imply a lost of state sovereignty and territorial integrity. Global Civilizational State has no intention of changing the status and privileges of state governments. In fact, state governments become primary members of Global Community. Earth governance is a balance between the rights of nation-states with rights of people and the interests of nations with the interests of Global Civilizational State. Global Parliament and the Federation of Global Governments would be the place of meeting between Global Governments. The power of the Federation was de-centralized to give each Global Government a better chance to find right solutions to global issues in its specific area and to take a larger share of responsibility and be more accountable to the people of the region where it operates. A Global Government is concerned not only with economics and trade, but also with the environment, health, agriculture, energy, as well as social, cultural and many other essential aspects. [1, 4, 6-11]

\section{Human Evolution}

The oldest known evidence of social units ever existed show that humans were adapting and evolving with time through generations. Civilization and culture both refer to the overall way of life of people and involve the values, beliefs, norms, institutions, social structures, and modes of thinking of successive generations in a given society. As such, a civilization is the most extensive cultural entity and, therefore regions, ethnic groups, nationalities, religious groups, all have distinct cultures. A civilization being the highest cultural grouping of people is defined by language, history, religion, customs and institutions. The composition and shapes of civilizations change over time. The cultures of peoples interact and overlap. Empires rise and fall, governments come and go, but civilizations remain and survive political, social, economic and even difficult ideological changes. Global Civilizational State implies the cultural coming together of humanity and the acceptance of common values, beliefs, orientations, practices and institutions by people throughout the world. Human beings in almost all societies share basic values. $[1,9,11,12]$

\section{Evolutionary Theory}

A variety of factors resulted in the eventual decay of the public sphere, including the growth of a commercial mass media, which turned the critical public into a passive consumer public; and the welfare state, which merged the state with society so thoroughly that the public sphere was squeezed out. It also turned the "public sphere" into a site of self-interested contestation for the resources of the state rather than a space for the development of a public-minded rational consensus. The process of modernization was forced through by economic and administrative rationalization so much that our everyday lives are penetrated by formal systems as parallel to development of the welfare state, corporate capitalism and mass consumption. Disfranchisement of citizens occurs as political parties and interest groups become rationalized and representative democracy replaces participatory one. In consequence, boundaries between public and private, the individual and society, the system and the lifeworld are deteriorating. Democratic public life cannot develop where matters of public importance are not discussed by citizens. An "ideal speech situation" requires participants to have the same capacities of discourse, social equality and their words are not confused by ideology or other errors.

While modernity epoch was inspired by the mechanistic and deterministic view of the universe emerging from modern science, postmodernity epoch has been born out of dissatisfaction with modernity and characterized by unsolved 
problems related to the global warming of the planet, globalization, political instability and a regress to irrationality. Evolutionity has proposed an alternative perspective encouraged by human social evolution and expanding global governance, including Global Solidarity. Evolutionity together with Global Civilizational State are a complex mix of higher levels of morality, religion, education, art, philosophy, technology and material wellbeing, and in fact both are a continuation of the previous epochs and both are proposing creative works toward saving humanity from self-destruction. [1, 2, 3, 4, 5, 9, 13]

\section{Evolutionary Society and Politics}

\subsection{Global Symbiotical Relationships}

The 21 st Century will see limitless links and symbiotical relationships with and within Global Community. The fundamental criteria is that a relationship is created for the good of all groups participating in the relationship and for the good of humanity, all life on Earth. The emphasis on the relationship gives more importance to the other aspects such as quality of life, protection of the environment and of the global life-support systems and the entrenchment of the Scale of Global Rights into our ways of life. Therefore, Symbiotical relationships are very crucial for humanity as they will determine our survival or not as a species and, consequently, the survival of the next generations. It is now increasingly evident that only by sharing the world's natural resources more equitably and sustainably we will be able to address both the ecological and social crisis we face as Global Civilizational State. The evolution of societies can be greatly accelerated by educating all Peoples worldwide. For now the Peoples of our world need to learn to live in symbiosis with one another. There are many types of symbiotical relationships to choose from. Relationships allow more stable and inclusive global economy.

A global symbiotical relationship is created between nation-states and the Federation for the good of all groups participating in the relationship and for the good of humanity, genuine group concerns and unconditional support for the individual's well-being, all life on Earth, a giant leap in human behaviour. The relationship allows a global equitable and peaceful development. [1, 8, 13-16]

\subsection{Proposal to Reform the United Nations to Be Under the Umbrella of Global Civilizational State and Global Parliament}

For the United Nations to be revitalized, something drastic needs to be done about the five permanent members of the UN Security Council. The major weakness of this Council lies in the fact that each one of these five members carries the power of the veto. This means if one of these five nations objects to the implementation of a law on a global scale, such a law cannot be implemented even if it would have the support of the rest of all the nations of the world! In essence, the welfare of the entire world as a top priority does not really mean anything by these permanent members of the UN Security Council. These countries are: United States, United Kingdom, Russia, China and France. [1]

Each one of them feels to be absolutely above the law and when it comes to doing what they want individually or collectively, they may become quite nasty and even dangerous. If we were to analyze the numerous vetoes these nations exerted, we will find out they served more to defeat the peaceful objectives of the United Nations rather than to promote them properly and effectively. This was done systematically to the detriment of the welfare of all people of the world without exception. For example, when the United Nations voted to abolish all nuclear weapons and all landmines, the United States objected and refused to accept such a plan. That was enough to destroy the chance for people everywhere to live in peace and security. [1]

Besides, these members of the UN Security Council hardly ever took the initiative to develop an international program of disarmament and arms control, even though the UN Charter advocates it. Needless to say, this could be easily understood since all the members of the UN Security Council deal with the business of the manufacture and sales of weapons, above all the United States. The eventual waging of wars has become a lucrative business! Today, wars are no longer waged to defend one's nations from unjust aggression. They are waged particularly by the United States because wars are now viewed as a lucrative business where one could make an enormous amount of money. [1]

Since there seems to be no chance that such permanent five members would ever consent on the total dismantling of their nuclear weapons, their permanent seat should be abolished the sooner the better. At the same time, we need to create a federation of nations, the Federation of Global Governments, Global Parliament, that firmly believes in world peace through education that comes through healthy Global Dialogues, abolition of hunger and poverty, provision of shelter for all the homeless, environmental protection and the safeguard of people's good health everywhere. [1]

The five permanent members of the UN Security Council must make a simple decision: give up their veto power and try to develop international programs that are in the best interest of all people without exception. This would certainly be a gigantic step toward peace where everyone will be a winner and no one will be a loser. The alternative would be for the five permanent members to continue to retain their veto power, doing what they always wanted to do, even to the detriment of millions of people around the world. [1]

\subsection{Earth Court of Justice, Global Law, and Global Constitution to Deal with all Aspects of Governance and Earth Management.}

In order to create a harmonious and compassionate Global Civilizational State, everyone needs to comply with Global Law. Global Law includes legislation covering all aspects of human activities. The Global Protection Agency (GPA) will train and lead a global force bypassing traditional peacekeeping and military bodies such as the United Nations 
and NATO. The GPA will enforce the law. And that is how Global Civilizational State can stop the global warming of the planet and protect the global life-support systems, thus largely improving the quality of life of the next generations. As we enact global law, we will begin to take on a much deeper kind of global leadership, one that earns more respect than envy and more gratitude than hatred, one that can catapult the whole planet forward into a future where war is no longer thinkable between nation-states and a legitimate and beneficial global government is able to cope with global problems. [1]

\subsection{Global Civilizational State: In a Multicivilizational World, It Is Best to Renounce Global Culture, Accept Diversity, and Seek Commonalities}

If the term civilization is elevated to what is common to humanity as a whole, then the largest cultural groupings of people would be a single Global Civilizational State, that is a variety of cultures, races, religious worlds, historical traditions, and historically formed attitudes. Over time, characteristics of Western civilization have been defined by religion and moral principles, human rights, language, ancestry, history, ethnic groups, customs and laws, maintaining a meaningful independent existence and ways of life. America is the distinct core-state civilization of the West. Inevitably, the fate of the United States and the West depends upon Americans asserting strongly once more their commitment to Western civilization and today, their commitment to the Global Civilizational State which is seen by global citizens as the guardian, custodian and embodiment of Western civilization. Historians, anthropologists, and other scholars have researched several core characteristics of civilization. [1]

Instead of promoting the supposedly global features of one global civilization, the requisites for cultural coexistence demand a search for what is common to most civilizations. It is a search for a Global Civilizational State. In a multicivilizational world, the better approach is to renounce global culture, accept diversity, and seek commonalities. There are core values which different ethnic and religious societies have in common. [1]

Leaders of the Western nations, especially of the United States believe that peoples from the non-Western civilizations should commit themselves to the Western values of democracy, free markets, limited government, human rights, individualism, the rule of law, and should embody these values in their institutions. A more inclusive Global Civilizational State can emerge gradually through the exploration and expansion of these commonalities. Peace in a multicivilizational world is the finding of commonalities: peoples in all civilizations should attempt to expand the values, institutions and practices they have in common with peoples of other civilizations. This effort would contribute to strengthening Global Civilizational State which is a complex mix of higher levels of morality, religion, learning, art, philosophy, technology and material wellbeing. [1]

\subsection{Cultural Commonality Legitimates the Leadership and Order-imposing Role of the Core State.}

A Global Civilizational State leadership in which core states play a leading or dominating role is a global government type world leadership. It is a leadership in which the exercise of influence by the core state is tempered and moderated by the common culture it shares with member states of its civilization. Cultural commonality legitimates the leadership and order-imposing role of the core state for both member states and for the external powers and institutions. In any given region of the planet where there is a dominant state, peace can be achieved and maintained only through the leadership of that core state. Regional power becomes responsible and legitimate when exercised by core states in relation to other members of their civilization. A core state can perform its ordering function because member states perceive it as cultural kin. Where core states exist, they are the central elements of the new international order based on civilizations, the Global Civilizational State. Now, in the proposal brought forward by the author of this Paper, it is clear here that Peoples from all over the world will keep their cultures within a specific Global Government. Global Parliament and the Federation of Global Governments would be the place of meeting between Global Governments of the different regions of the world. The power of the Federation was de-centralized to give each Global Government a better chance to find right solutions to global issues in its specific area and to take a larger share of responsibility and be more accountable to the people of the region where it operates. A Global Government is concerned not only with economics and trade, but also with the environment, health, agriculture, energy, social, cultural and many other essential aspects.

Today the evidence-based argument for the appearance of a Global Civilizational State is really the result of the broad processes of modernization and post modernization stages that have been going on since the eighteenth century. Modernization involves industrialization, urbanization, increasing levels of literacy, education, wealth, social mobilization, and more complex and diversified occupational structures. It is a product of the tremendous expansion of scientific and engineering knowledge beginning in the eighteenth century that made it possible for humans to control and shape their environment in totally unprecedented ways. The attitudes, values, knowledge, and culture of people in a modern society differ greatly from those in a traditional society. As the first civilization to modernize, the West leads in the acquisition of the culture of modernity. As other societies acquire similar patterns of education, work, wealth and class structure, so the argument runs that this modern Western culture will become the new culture for Global Civilizational State. Modern societies could resemble each other more than do traditional societies because the increased interaction among modern societies may not generate a common culture but it does facilitate the transfer of techniques, inventions and practices from one society to another with a speed and to a degree that were impossible in 
the traditional world. [1, 2, 7-12, 17-22]

There is no greater task in the world today than for Global Civilizational State to proceed through the maturation of its leadership, emerging from a more self-interested adolescence as a global leader into a nobler adulthood. We have the potential to act as a torchbearer for a better tomorrow. Do we heed the call? It is hope this assessment has convinced at least a few people that the question of how to proceed with that maturation is of far deeper significance than the reforming of the United Nations. Let us move forward with wisdom, grace, clarity and love in the days, years, and even decades ahead. [1]

\subsection{Globalization: Capitalism Is at the Core of This Unsustainable System}

Globalization is a process which involves growing economic interdependence of countries worldwide with implications and impacts on social, cultural, political, environmental and familial aspects and rights. With the globalization of the economy comes now the task for defining the obligations that go with the rights. This phenomenon is also present in the arena of international finance. In this area, however, the presumed virtues of globalization are far from being materialised. Until now, no orderly or stable financial system has been implemented. Furthermore, the current financial system does not succeed in channelling sufficient funds to finance crucial world problems such as adequate social development in poor countries. In consequence of globalization, the new economic and political distribution of power around the world has become very different then we were used to. Giant new markets are forming all over the world. Competition is hardening. National economies can no longer insure or guarantee rights of possession on any property. National borders no longer mean protection, security, cultural boundaries, resources ownership, political and economic control. We need to recognize the failure of fundamental systems, and to abandon the notion that what there is to do is to recalibrate the national and international institutions that structure our lives today. Indeed, we need to realize that the way we thought things would work out is long gone. Capitalism is at the core of this unsustainable system. It gives rise to the high-energy/mass-consumption of privileged societies. [17-19, 21-26]

\subsection{A New Impetus Given to the Way of Doing Business and Trade in Line with a Democratic Socialism Plus"}

Let us now define what economic system should be used to govern our planet. What would be best is a "democratic socialism plus". The "plus" means added essential elements for governing sustainably. For instance, people would have free health care, free education at all levels and employment for everyone. People would control and manage natural resources at all stages: exploration, production, transportation, manufacturing and distribution. A Global Trade and Resource Ministry would be formed to look after the management of natural resources worldwide and global trade. "Democratic socialism plus" advocates that the control and management of natural resources be under the control of the people. This new way of governing can be achieved through legitimate democratic means by voting in a party that represents this way of governing. "Democratic socialism plus" implies public, not private ownership of natural resources. Yet, the main reason that this global crisis will be curbed is a simple one: infinite growth, whether economic growth or population growth, cannot continue indefinitely. Anyone who believes exponential growth can go on forever in a finite world is either a madman or an economist. Accordingly, one can envision that a global crash is coming. In large measure, it's because environmental tipping points are on the way $[1,26]$.

Although in theory the capacity development for peace building in post-conflict nations or societies seems to be logical, in practice things are different. Let us illustrate this by example. Over the last 6,000 years of recorded history, the institution of the military has always served for negative and destructive purposes. Hence, its very existence assures the continuation of the culture of war, that is, of constantly resorting to war to solve human conflicts or problems. The presence of the military has always had a negative and destructive connotation throughout history. It is the only institution that can disregard all laws without being penalized afterwards. It disregards the natural law as the manufacture of weapons does emit in the atmosphere tons of toxic wastes that, in the United States alone, has caused cancer to some two million people a year. $[1,8,10,13-15,17,22,24,27]$

\subsection{Formation of Global Ministries in all Important Global Commons of Our Lives}

The formation of global ministries is the most important event in human history. Global Civilizational State values did not all exist at first during the early stage of human evolution. Most of them gradually developed over time. Today, it is not just about 'humanity survival' but also 'all lifeforms survival' on Earth we are fighting for. We need to create a Global Ministry for the economic sharing, production and distribution of resources on our planet. A Global Trade and Resources Ministry is needed urgently to look after the global sustainable management of Earth resources at all stages: exploration, production, transportation, manufacturing, distribution and economic sharing. In fact, we need global ministries for the proper management of the most important global commons. Global ministries will be given power to rule themselves in harmony with each other. $[1,20$, 28]

\subsection{Trade Partners to Become Legally and Morally Responsible and Accountable for Their Products from Beginning to End}

Over its long past history trade has never evolved to require from the trading partners to become legally and morally responsible and accountable for their products from 
beginning to end. At the end the product becomes a waste and it needs to be properly dispose of. Now trade must be given a new impetus to be in line with the global concepts of the Global Civilizational State. When you do exploration work and develop, manufacture, produce, mine, farm or create a product, you become legally and morally responsible and accountable for your product from beginning to end (to the point where it actually becomes a waste; you are also responsible for the proper disposable of the waste). This product may be anything and everything from oil \& gas, weapons, war products, construction products, transportation and communication products and equipment, to genetically engineered food products. All consumer products! All medical products! All pharmaceutical products! In other words, a person (a person may be an individual, a community, a government, a business, an NGO, or an institution) becomes responsible and accountable for anything and everything in his or her life. [1]

\subsection{Social Responsibilities and Accountabilities of Consumers}

Just as corporations have social responsibilities and so do consumers in societies. Consumers are socialized to improve the quality of their lives. Quality of life is a multidimensional, complex and very subjective concept. For instance, people who have changed their consumption habits to ensure that their choices will make a better quality of life for themselves, the environment and future generations, may be seen by others as having a lower or inferior quality of life since they have removed themselves from the materialistic mainstream characteristic of our consumer society. They may feel that an absence of violence and abuse in their life leads to a higher quality of living even though they have fewer tangible resources, money, or shelter; peace of mind and freedom from abuse has increased the quality of their daily life relative to what it was like before. There are universal quality of life values which lead to "human betterment" or the improvement of the human condition. They include: adequate resources, justice and equality, freedom and peace or balance of power. A better quality of life for all people of the Global Civilizational State is a goal for all of us and one of our universal values. [1]

Individuals, too, can help bring about a world that is more secure and more supportive of life, health and happiness. They can educate themselves on population dynamics, consumption patterns and the impact of these forces on natural resources and the environment. They can be socially, politically and culturally active to elevate the issues they care about. They can become more environmentally responsible in their purchasing decisions and their use of energy and natural resources. And individuals and couples can consider the impacts of their reproductive decisions on their communities and the world as a whole. [1]

Comprehensive population policies are an essential element in a world development strategy that combines access to reproductive health services, to education and economic opportunities, to improved energy and natural resource technologies, and to healthier models of consumption and the "good life." [1, 12, 20]

\section{Tractatus Politco-Philosophicus}

In several private communications to the author of this Paper, Professor W. Julian Korab-Karpowicz has described the term "Evolutionity" and wrote that it is no longer related merely to the transformation of matter or the biological improvement of bodies, but also proceeds through the development of our minds, as seen in our scientific and technological achievements, the effects of which we can see every day. However, the expansion of scientific knowledge is not enough if ethics is lacking. To continue with our evolution, we also need to create cultural environments and social conditions in which individual human beings can fully develop morally and intellectually and continuously make progress from one to another generation. He also discussed global issues in his book Tractatus Politco-Philosophicus. To name just a few, these are: politics, human nature, the state, freedom, solidarity, democracy, civilization, war and peace. The main objective of the work is to demonstrate the necessity and provide a guide for the redirection of humanity. He argues that this paradigm shift must involve changing the character of social life and politics from competitive to cooperative, encouraging moral and intellectual virtues, providing foundations for happy societies, promoting peace among countries and building a strong international community. He has shown that the essence of politics is not a struggle for power but rather the ability to organize society for cooperation. He proposed that the new positive world transformation must be a moral transformation based on the correct recognition of our true identity as human beings. On the practical level, the United Citizens (UC) organization would provide a foundation for the Global Solidarity Movement that should not be grounded in any ideology, but in inclusive values uniting all human beings derived from the basic human need for happiness or self-realization. Global Solidarity does not necessitate the replacement of the present international system with a world state or the creation of a new global authority but is an addition to the current model of global governance that has already been provided by the UN. Global Solidarity obliges us to defend and enhance life against those forces that are destructive of life and human evolution and to exert pressure on governments, so that they support international organizations and consider the welfare of all humanity. [1-5]

\section{Process Philosophy}

\subsection{When Looking Across Cultures of Geo-cultural Areas and Across Millennia, Certain Virtues have Prevailed in all Cultures}

From ancient time to this day, morality in society made its way into our ways of doing business. So the set of behaviors that constitute Global Civilizational State ethic for a business 
also evolved largely because they provided possible survival benefits to increase evolutionary success. Consequently, peoples evolved socially to express emotions, such as feelings of empathy or guilt, in response to these moral behaviors. Humans developed truly moral, altruistic instincts. When looking across cultures of geo-cultural areas and across millennia, certain virtues have prevailed in all cultures, the major ones include [1]: wisdom, knowledge, courage, justice, love, truth, empathy, kindness, and social intelligence.

These virtues were not always incorporated into the ways of doing business because the $1 \%$ super rich businesses became corrupted, greedy, no longer in line with humanity's survival on the planet. The $1 \%$ super rich people worldwide, who thrive within capitalism, must be overthrown. But today, Global Civilizational State incorporates these virtues and proper behaviors into corporate citizen global ethics.

\subsection{To Let Go the Notion that What There Is to Do Is to Recalibrate the Institutions that Structure Our Lives Today}

Is our system of governance a sustainable system? We need to recognize the failure of fundamental systems and to let go the notion that what there is to do is to recalibrate the institutions that structure our lives today. Somewhat like the US Congress is doing. Put money into the system and everything will be fine! We need to realize that the way we thought things would work out truly is gone. Capitalism is at the core of this unsustainable system. It gives rise to the highenergy/mass-consumption of privileged societies. We must setup measures to stop speculators benefiting from the misery of others, by punishing corrupt politicians. Ultimately, unless we begin to see the world as a whole, in which things are truly interconnected, our governments will continue their hostilities, oil prices will keep on rising, and when the time comes for us to complain, we will be faced with the guns of the police whom we have helped to create with the payment of our taxes. [1]

\subsection{Human Morality, Ethics, and Global Community State}

Human morality is a natural phenomenon. On the understanding that Global Community ethics are sets of selfperpetuating and biologically-driven behaviors which encourage human cooperation and symbiotical relationships, then we all can see why Global Community concepts and approaches to humanity's survival become so urgently needed today.

All social beings have modified their behaviors by restraining immediate selfishness in order to improve their evolutionary fitness. This is why humanity needs to correct the present business world and corporate citizens as most of the wealth on the planet is in the hands of the $1 \%$ of the world population while the remaining $99 \%$ of the people are badly taken advantage of. [1]

Human morality though sophisticated and complex relative to other lifeforms, is essentially a natural phenomenon that evolved to restrict excessive individualism of the $1 \%$, including their human rights, that could undermine a group's cohesion and thereby reducing all life's survival on our planet.

After making the proper adjustment to ways of doing business in the world, morality can then be defined as an accumulation of interrelated behaviors that cultivate and regulate complex interactions within social groups. These behaviors includes empathy, reciprocity, altruism, cooperation, a sense of fairness, symbiotical relationships, and have been included directly into the corporate citizen global ethics.

A more inclusive Global Civilizational State can emerge gradually through the exploration and expansion of commonalities. Peace in a multicivilizational world requires finding of commonalities between peoples in all civilizations and expanding the values, institutions and practices they have in common with peoples of other civilizations. This effort would contribute to strengthening Global Civilizational State which is a complex mix of higher levels of morality, religion, learning, art, philosophy, technology and material wellbeing. [1]

Modern morality and ethics are closely tied to the sociocultural evolution of different Peoples on our planet. Morality is therefore a product of evolutionary forces acting at an individual level and also at the group level through group selection. The set of behaviors that constitute morality evolved largely because they provided possible survival and/or reproductive benefits to increase evolutionary success.

Global Civilizational State ethics for a business are about how we treat others and about a commitment to respect every person humanely and with dignity. For this process to work, global citizens learn to forgive, be patient and compassionate, promote acceptance, open theirs hearts to one another, and practice a culture of solidarity and cooperation. We should let go narrow differences between us all for the greater good of humanity and future generations. [1]

The increased interaction among peoples which includes trade, investment, tourism, media, electronic communication, is generating a common world culture. Improvements in transportation and communications technology have indeed made it easier and cheaper to move money, goods, people, knowledge, ideas and images around the world. [1]

People in most societies have a strong moral sense, a morality of basic concepts of what is right and wrong. If people have shared a few fundamental values and institutions throughout history, this may explain some constants in human behavior but it cannot explain history, which consists of changes in human behavior. If a Global Civilizational State common to all humanity exists, what term do we then use to identify the major cultural groupings of humanity? Humanity is divided into subgroups such as tribes, nations, and broader cultural entities usually called civilizations. If the term civilization is elevated to what is common to humanity as a whole, then the largest cultural groupings of people would be a single Global Civilizational State that is a variety of cultures, peoples, religious worlds, historical 
traditions and historically formed attitudes. Confusion occurs by restricting 'civilization' to the global level and designing as 'cultures' or 'subcivilizations' those largest cultural entities which have historically always been called civilizations. [1]

Global Civilization State has extended the idea of sustainability to be a moral and ethical state as well as an economic and environmental state. We invite everyone and every organization to participate openly without fear. Paticipate in the process of the Global Dialogue. Again today we ask everyone throughout the World to scrutinize all of their values. No exception! You are asked to create new thoughts that will sustain Earth, humanity and all Life. [1]

\subsection{Harmonious Peace order: Harmonize Diversity with Unity, the Exercise of Freedom with the Common Good, Short-term Objectives with Long-term Goals}

Global Community claims that everyone on Earth should be able to live in peace. This Global Peace Movement is about courage to live a life in a harmonious peace order and showing by example, thus preventing poverty, wars, terror and violence. We need to educate the coming generations with good principles, compassion, social harmony and global sustainability being some of them. [1]

Human interactions often involve differences between important values. This can mean difficult choices. However, we must find ways to harmonize diversity with unity, the exercise of freedom with the common good, short-term objectives with long-term goals. Every individual, family, organization, and community has a vital role to play. The arts, sciences, religions, educational institutions, media, businesses, nongovernmental organizations, and governments are all called to offer creative leadership. The partnership of government, civil society and business is essential for effective global governance based on this creative leadership. [1]

\subsection{Science has a Responsibility for the Well-being of Humanity}

Science has a responsibility for the well-being of humanity. Science gives a person a set of rules, a way of thinking, a philosophy to look at the physical universe, to observe and analyze it, and to discover its making, its functioning, and its structure. The scientific method is very reassuring to oneself. It gives us the basic reasoning we need in order to make informed and sound policy and management decisions. Science is found everywhere in our societies. Because of science, new technologies and techniques were developed and used in the market place.

Science hardly has its own philosophical precepts, particularly the notions of Uniformity of Law and of Uniformity of Process across time and space. "We have to realize that a unified theory of the physical world simply does not exist," said Feyerabend; "we have theories that work in restricted regions, we have purely formal attempts to condense them into a single formula, we have lots of unfounded claims (such as the claim that all of chemistry can be reduced to physics), phenomena that do not fit into the accepted framework are suppressed; in physics, which many scientists regard as the one really basic science, we have now at least three different points of view... without a promise of conceptual (and not only formal) unification".

The products of science take important places in all aspects of our lives and actually save lives every second. They make our lives manageable in a million different ways. Science has also played a destructive role in our history and is continuing to do so today. Science, technology and engineering are directly or indirectly responsible for threats to our environment, for wasteful uses of the Earth's resources and for wars and conflicts in the world.

Science, technology and engineering are major forces of socio-economic change. They cause humanity and its social and natural environment to evolve rapidly and, therefore, they carry serious responsibility and accountability. They are no longer regarded as benefactors of humanity. Ethical integrity has declined. In several parts of the world people have become suspicious and are questioning abuses of various kinds. Many scientists and other professionals have shown little regard to ethical problems arising from their work but they must become responsible and accountable just like everyone else. There are no exceptions. We are all asked in helping humanity and all life on Earth from complete extinction. It is a common goal. [1, 17, 23, 24, 25, ]

Science, technology and engineering must regain public trust, state ethical responsibilties and become a voice to present and future generations. Continuous discussions are needed on the ethical issues related to science, technology and engineering, their practices and ideologies.

\subsection{Scale of Global Rights}

Over the past several decades humanity has bettered itself through the acceptance of the Universal Declaration of Human Rights by most nations. But now is the time to leave it behind and reach to our next step of social evolution, that is the approval of a scale of social values, the Scale of Global Rights. [1]

Primordial human rights on the Scale are separate categories from those of community rights, the right of the greatest number of people, economic rights, social rights, cultural rights and religious rights. Ecological and primordial human rights are the only rights that have existed unchanged throughout the evolutionary origin of our species. Any major change would have threatened our very existence. All other human rights are rights created by human beings and can be changed depending of new circumstances; they are not stagnant but are rather flexible and adaptive, and they can evolve. Ecological and primordial human rights of this generation and of future generations are therefore much more important than any other human rights existing now and in the future. [1]

Global Civilization offers short and long term solutions to the people of all nations to assure the survival of life on Earth. Both solutions require the acceptance of the Scale of Global Rights as our guide for survival. As a first step, all 
nations should approve the first three sections on the Scale of Global Rights. The approval would also supersede the political and physical borders of participating member nations. The approval would mean politics and justice without borders only concerning those three sections. [1]

In this way the Scale of Global Rights gives us a sense of direction for future planning and managing of the Earth. Earth management is now well defined and becomes a goal to achieve. We no longer waste energy and resources in things that are absolutely unimportant. It has also become a necessity of establishing the Global Trade and Resources Ministry that will be assessing, compiling, managing and protecting Earth resources, and the Earth Court of Justice prosecuting cases involving crimes related to the relentless misused of the Earth resources. [1]

Global Civilizational State found evidence that the ecological base is the essential prerequisite for the effectiveness and exercise of all rights recognized for human beings. The stewardship of the ecological base has to be given priority before the fulfilment of various economic and social wishes. Demands resulting from the socio-economic system of a particular country have to find their limits in the protection of the global ecosystem. Vital interests of future generations have to be considered as having priority before less vital interests of the present generation. Supply chains have to be designed in a way that the goods can enter after usage or consumption into natural or industrial recycling processes. If serious damages to persons, animals, plants and the ecosystem cannot be excluded, an action or pattern of behaviour should be refrained from. A measure for supplying goods or services should choose a path which entails the least possible impact on the ecological and social system concerned. This way functioning proven systems will not be disturbed and unnecessary risks will not be taken. Supply strategies consuming fewer resources should have preference before those enhancing more resource consumption. When there is a need to find a solution to a problem or a concern, a sound solution would be to choose a measure or conduct an action, if possible, which causes reversible damage as opposed to a measure or an action causing an irreversible loss. [1]

The Scale of Global Rights contains six (6) sections. Section 1 has more importance than all other sections below, and so on. [1]

Concerning sections 1, 2, and 3, it shall be Global
Parliament highest priority to guarantee these rights to Member Nations and to have proper legislation and implement and enforce Global Law as it applies.

Section 1. Ecological rights and the protection of the global life-support systems

Section 2. Primordial human rights

It is made clear how little importance was given to Sections 1,2,3 and 4 of the Scale of Global Rights. And it is made clear how urgent it is to replace both the Universal Declaration of Human Rights and Charters from all nations by the Scale of Global Rights.

1. safety and security

2. shelter

3. 'clean' energy

4. a 'clean' and healthy environment

5. fresh water

6. clean air

7. balanced diet

8. basic clothing

9. employment, health and free education for everyone.

Section 3. The ecological rights, the protection of the global life-support systems and the primordial human rights of future generations

Concerning Sections 4, 5 and 6, it shall be the aim of Global Parliament to secure these other rights for all global citizens within the federation of all nations, but without immediate guarantee of universal achievement and enforcement. These rights are defined as Directive Principles, obligating Global Parliament to pursue every reasonable means for universal realization and implementation.

Section 4. Community rights, rights of direct democracy and global voting, the right that the greatest number of people has by virtue of its number (50\% plus one) and after voting representatives democratically

Section 5. Economic rights (business and consumer rights, and their responsibilities and accountabilities) and social rights (civil and political rights)

Section 6. Cultural rights and religious rights

The following table is a comparison of the importance of the Universal Declaration of Human Rights and the Scale. It is made clear how little importance was given in the Universal Declaration to Sections 1, 2, 3 and 4 of the Scale of Global Rights. And it is made clear how urgent it is to replace both the Universal Declaration of Human Rights and Charters from all nations by the Scale of Global Rights.

Table 1. Comparison between the Scale of Global Rights and the Universal Declaration of Human Rights and Charters from all nations. [1].

\begin{tabular}{|c|c|c|}
\hline \multicolumn{3}{|c|}{$\begin{array}{l}\text { Importance of the Universal Declaration of Human Rights on the Scale of Global Rights } \\
\text { The total degree of importance due to the Universal Declaration. }\end{array}$} \\
\hline Scale & Articles of the Universal Declaration of Human Rights & Total degree of importance of the Universal Declaration of Human Rights \\
\hline Section 1 & parts of Article $3 ; 1 \%$ importance & $1 \%$ importance \\
\hline Section 2 & parts of Articles $3,4,5,9,13,14,25 ; 35 \%$ importance & $35 \%$ \\
\hline Section 3 & no Articles; $0 \%$ & $0 \%$ \\
\hline Section 4 & parts of Articles $16,18,21,29 ; 5 \%$ & $5 \%$ \\
\hline Section 5 & parts of Articles $15,17,20,21,22,23,24,28 ; 100 \%$ & $100 \%$ \\
\hline
\end{tabular}

Here is how the degree of importance was obtained. For instance in Section 1 it was found that parts of Article 3 of the Universal Declaration of Human Rights was included as promoting very softly the protection of human life but was 
not promoting at all the protection of the global life-support systems. Section 1 on the Scale of Global Rights promotes both the protection of human life and the global life-support systems. No key rights were found in the Universal Declaration that would promote in any way the protection of human life and that of the global life-support systems. And it is a failure of the Universal Declaration to be in line with the Scale of Global Rights. As a result of this failure, a $1 \%$ importance was recorded in the table. What does it mean? It means that the Universal Declaration does not give any importance to human life and the protection of the global life-support systems. These results are consistent and in agreement with the fact that democracies hardly survive overpopulation such as are being seen in the world. What happens to the idea of the dignity of the human species if this population growth continues at its present rate? It will be completely destroyed. Democracy cannot survive overpopulation. Human dignity cannot survive overpopulation. Convenience and decency cannot survive overpopulation. As you put more and more people onto the world, the value of life not only declines, it disappears. It doesn't matter if someone dies, the more people there are, the less one person matters. [1]

\section{Conclusion}

Global Civilizational State has now a Vision of the Earth in Year 2024 and a sense of direction, and embarks on a new path in history. The inevitability of global societies that are living, sharing and creating symbiotical relationships interactively is, beyond doubt, what we must resolutely and heartily accept. Our creativity today may influence tomorrow's socio-economic strategies and contribute to the evolution of human societies, - an evolution directed towards a global partnership and cooperation with each other for survival.

Our time is about the courage to live a life in a harmonious peace order and showing by example, thus preventing poverty, wars, terror and violence. We need to educate the coming generations with good principles, show compassion, and demonstrate social harmony and global sustainability.

The world is in the global crisis. We are exploiting our natural resources, minerals and fuels faster than we are gaining access to alternative sources. We are polluting the natural environment faster than the environment can regenerate itself to reach the level suitable for human needs. We are changing climate dangerously. Our attitude and way of life show a moral degradation toward the existing forms of life on the planet. It's time for us to protect what is left to protect: life itself on Earth. This is the reason for the creation of biodiversity zones all over our planet.

We need ways of organizing ourselves to help us live in a world with less energy and to grow strong caring communities in which we get more of our human satisfaction from caring relationships and less from material goods. We need to reclaim the ideal of being a democratic middle-class people without extremes of wealth and poverty. We need to recover a deep sense of community that has disappeared from many of our lives. This means letting go a sense of ourselves as consumption machines. We need a Global Civilizational State leadership for all of humanity.

Effective Earth governance requires a greater understanding of what it means to live in a more crowded, interdependent humanity with finite resources and more pollution threatening the global life-support systems. Global Civilizational State has no other choice but to work together at all levels. The collective power is needed to create a better world. Let us all work together to build a greater and most trusty Global Civilizational State. Humanity needs urgently this world system of governance.

The United Nations failed to satisfy the needs of the people of the 21st Century. It has never improved upon the old 20th Century ways and thinking. Its voting system no longer satisfies the 7 billion people on Earth. The challenges are different now and require a world organization capable of dealing with the needs of all Peoples. We need a Global Civilizational State.

Global Civilizational State opposes environmental, economic, population and military warfare and it was first to oppose any type of invasion of a people by another people. An invasion is either an environmental, economic, population or military offensive in which large numbers of combatants of one geopolitical entity aggressively enter territory owned by another such entity, generally with the objective of either conquering; liberating or re-establishing control or authority over a territory; forcing the partition of a country; altering the established government or gaining concessions from said government; or a combination thereof. An invasion can be the cause of a war, be a part of a larger strategy to end a war, or it can constitute an entire war in itself. Due to the large scale of the operations associated with invasions, they are usually strategic in planning and execution. Global Civilizational State has been witnessing such different types of warfare for decades. And now is the time to stop all types of invasion no matter what they maybe.

For the first time in human history, in 1985 Global Civilizational State has proposed a benchmark:

* formation of global ministries in all important global commons of our lives

* the Scale of Global Rights as a replacement to the Universal Declaration of Human Rights

* Earth Court of Justice, Global Law, and Global Constitution to deal with all aspects of governance and management of the Earth

* a new impetus given to the way of doing business and trade in line with a "democratic socialism plus"

* geographical, economical, political, social, business, religious symbiotical relationships between nations, communities, businesses, and Peoples for the good and wellbeing of all

* proposal to reform the United Nations to be under the umbrella of Global Civilizational State and Global Parliament 
Let our time be a time remembered for the awakening of a new reverence for life, the firm resolve to achieve sustainability, the quickening of the struggle for justice and peace, and the joyful celebration of life. Let our expanding consciousness blend with that of the Soul of Humanity.

\section{References}

[1] Dufour, Germain J., President of Global Community, Global Civilization, Global Civilization State; Business website of Global Community WebNet Ltd., Federally incorporated in Canada, found at: http://globalcommunitywebnet.com/ Dialogue2020/index.html Listing of Global Community achievements since 1985: All Global Dialogues found in Global Community Proceedings http://globalcommunitywebnet.com/ GIMProceedings/ and http://globalcommunitywebnet.com/

globalcommunity/globaldialogue.htm and all achievements were listed in monthly Newsletters at: $\mathrm{http} / / /$ globalcommunitywebnet.com/

Dialogue2019/Newsletters/August2019/index.html

[2] Korab-Karpowicz, W. Julian "The Clash of Epochs: Traditional, Modern, Postmodern, and Evolutionity." Private communications. Received January 17, 2020 from Poland.

[3] Korab-Karpowicz, W. Julian "Evolutionity - The New Evolutionary Age for Humanity A proposal for a new model of global governance and for solving global challenges." Private communications. Based on "Tractatus PoliticoPhilosophicus". Received January 17, 2020 from Poland.

[4] Korab-Karpowicz, W. Julian "Tractatus PoliticoPhilosophicus: New Directions for the Future Development of Humankind." New York, NY Routledge 2017.

[5] Korab-Karpowicz, W. Julian "Evolutionity - A New Age of Humanity: On the Concept of Human Evolution by HoeneWronski." Private communications. Received January 17, 2020 from Poland.

[6] Almand, Eugenia "Global Parliament and Global Governments Federation." Private communications. Received July 13, 2005 from Mexico. http://globalcommunitywebnet.com/gdufour/2005Almand.htm

[7] Avery, John Scales "A world federation". Private communications. Received November 19, 2018 from Denmark. http://eacpe.org/a-world-federation/ http://eacpe.org/app/wp-content/uploads/ 2018/11/A-WorldFederation-by-John-Scales-Avery.pdf Scale of Global Rights, and Universal Declaration of Human Rights. http://globalcommunitywebnet.com/globalcommunity/Scale.ht $\mathrm{m}$ http://globalcommunitywebnet.com/globalrights/scale.htm

[8] Ellis, Dr. Michael "Global Security, Globalization and Planetary Demise." Private communications. Received September 4, 2001 from United States. http://globalcommunitywebnet.com/ PeaceNow/Ellis.htm

[9] Huntington, Samuel P. "The Clash of Civilizations and the remaking of World Order". New York, NY Simon \& Schuster Paperbacks, 2011.

[10] Rebello, Dr. Leo "Common values in different religions." Private communications. Received March 3, 2008 from India. http://globalcommunitywebnet.com/ PeaceNow/Rebello.htm
[11] Weiwei, Zhang "The China Wave. Rise of a Civilizational State". Hackensack, NJ: World Century Publishing Corporation, 2012.

[12] Coker, Christopher "The Rise of the Civilizational State". Cambridge, UK: Polity Press 2019.

[13] Mercieca, Dr. Charles "Creating World Peace and Harmony" Private communications. Received April 15, 2014 from United States. http://globalcommunitywebnet.com/ PeaceNow/Mercieca.htm

[14] Crequie, Guy "PRINCIPE D'HARMONIE ET REALITE SOCIALE = LE CHEMIN DE LA TRANSFORMATION." Private communications. Received 26 janvier 2007 from France. http://globalcommunitywebnet.com/ PeaceNow/Crequie.htm

[15] Semashko, Dr. Leo "A new culture of peace, preventing wars, terrorism and poverty." Private communications. Received December 21, 2008 from Russia. http://globalcommunitywebnet.com/ PeaceNow/Semashko.htm\#peaceculture

[16] Simond, Mme Gabrielle "Cercle Universel des Ambassadeurs de la Paix." Private communications. Received November 27, 2008 from France. http://globalcommunitywebnet.com/ PeaceNow/Simond.htm

[17] "The future of democracy, with Jürgen Habermas". KNAW. Retrieved 6 November 2013. Kloveniersburgwal 29, $1011 \mathrm{JV}$ Amsterdam.

[18] Marx, Karl. "Capital: A Critique of Political Economy." Trans. Moore, Samuel, Edward Aveling and Friedrich Engels. Marxists.org, 2015 (1867).

[19] Marx, Karl, and Friedrich Engels. "The Communist Manifesto." Trans. Moore, Samuel and Friedrich Engels. Marxists.org, 2000 (1848).

[20] Michnowski, Leslaw "GLOBAL GOVERNANCE AND INFORMATION FOR THE WORLD SOCIETY'S SUSTAINABLE DEVELOPMENT" Private communications. Received January 1, 2000 from Poland. http://globalcommunitywebnet.com/

PeaceNow/Michnowski.htm

[21] Schumpeter, Joseph A. "Capitalism, Socialism and Democracy." London: Routledge, 2010 (1942).

[22] Weber, Max. "Politics as Vacation." Trans. H. H. Gerth, and C. W. Mills. New York: Free Press, 1946.

[23] Esping-Andersen, Gosta. "The Three Worlds of Welfare.

[24] Feyerabend, Paul (1987). Farewell To Reason. Verso. p. 100. ISBN 0-86091-184-5.

[25] Friedman, Milton. "Capitalism and Freedom," Fortieth Anniversary Edition. Chicago: University of Chicago Press, 2002 (1962).

[26] Sanders, Bernie " Bernie Sanders is an American politician who has served as the junior United States Senator from Vermont since 2007. The U.S. Representative for the state's atlarge congressional district from 1991 to 2007 , he is the longest-serving independent in U.S. congressional history and a member of the Democratic caucus." Private communications. Received February 3, 2020 from the United States. https://berniesanders.com/ 
[27] Allison, Dana, Farida, Gael, Jodie, Katie, Medea, Nancy, Rae, Samantha and Tiffany, "Change Is... Sustaining Peace." Private communications. Received June 15, 2006 from United States. http://globalcommunitywebnet.com/ PeaceNow/CodePink.htm

[28] Vargas-Hernández, Dr. José G. "CO - OPERATION AND
CONFLICT BETWEEN FIRMS, COMMUNITIES, NEW SOCIAL MOVEMENTS AND THE ROLE OF GOVERNMENT THE CERRO DE SAN PEDRO CASE"

Private communications. Received January 19, 2006 from Mexico. http://globalcommunitywebnet.com/ PeaceNow/VargasHernandez.htm 